\title{
Trilophidius gemmatus sp. n., a new species from Bhutan, with an updated identification key to the Asian species (Coleoptera, Carabidae, Scaritinae)
}

\author{
Michael Balkenohl ${ }^{1}$ \\ 1 Ligusterweg 9, CH-8906 Bonstetten, Switzerland \\ http://zoobank.org/D3A2185B-8876-4330-8A7B-BD175B86F49B \\ Corresponding author: Michael Balkenohl (mike.balkenoh|@bluewin.ch)
}

Received 20 July 2017

Accepted 29 September 2017

Published 20 November 2017

Academic editor:

Christoph Germann

\section{Key Words}

Trilophidius

Carabidae

Clivinini

taxonomy

species description

alpine altitudinal belt

Himalaya

\section{Abstract}

Trilophidius gemmatus sp. n. from Bhutan is described and illustrated. Notes on how to separate this species from other Asian Trilophidius species are given. An updated identification key to the Asian Trilophidius species is provided.

\section{Zusammenfassung}

Trilophidius gemmatus sp. n. aus Butan wird beschrieben und abgebildet. Die Art wird differentialdiagnostisch von den anderen asiatischen Arten abgegrenzt. Der Bestimmungsschlüssel der asiatischen Trilophidius-Arten wird aktualisiert.

\section{Introduction}

The genus Trilophidius Jeannel, 1957 comprises twenty-two species divided into two species-groups. The impunctatus species group is known to occur in Asia with seven species and the congoanus species group in Africa with fifteen species. Asian species have been revised sixteen years ago and a catalogue of the species from both continents was provided (Balkenohl 2001). Very recently, two new species were described from Equatorial Guinea (Grebennikov et al. 2017).

In Asia occurrence is known from East India to South China and southwards to southern Malaysia and Sumatra. Records were also taken from Sri Lanka, Palawan, and Borneo (Balkenohl 2001). Two species, Trilophidius cervilineatus Balkenohl, 2001 and T. minutulus Balkenohl, 2001 occur at the border to the Palaearctic
Region (Guangdong, China) (Balkenohl in press). The new species was found in Bhutan (Thrumshingla National Park, $\sim 2500$ meters). It is the first example that the genus inhabits in Asia higher mountainous regions and not only lowland habitats. It is as well another example for the distribution of the genus close to the Palearctic Region.

The species are tiny $(2-2.6 \mathrm{~mm})$ and morphologically not easy to distinguish due to their relative poverty of striking characters. In contrast to the African species, all Asian species exhibit fully developed wings, and they are sometimes collected at light. Like most of the Clivinini, they inhabit humid terrestrial habitats, but knowledge about their way of living is extremely poor.

Recently, Werner Marggi and Hans Hebauer kindly brought new material to my attention. Investigation revealed the Trilophidius material of both of the collectors is con- 
specific and represents a new species. Beside the description, this contribution has the goal to provide an update to the identification key to the Asian species and to enrich the knowledge of the distribution provided sixteen years ago.

\section{Material and methods}

The material at hand consists of eight specimens. The Asian species were revised earlier by the author (Balkenohl 2001), and paratypes or specimens are present for comparison in CBB.

The material is deposited in the following collections:

CBB Coll. Michael Balkenohl, Bonstetten near Zürich, Switzerland;

CHR Coll. Hans Hebauer, Rain, Germany; NMBE Natural History Museum Bern, Switzerland.

In general, terms, descriptions of characters and mounting methods are based on Balkenohl (2001), where the genus description is provided as well.

Specimens were examined with a Leica M205-C stereomicroscope. Magnifications were used up to 160 times, with the iris diaphragm usually closed up to $20 \%$. This provides sufficient sharpness for some of the very small characters of these tiny beetles, for example to distinguish setigerous punctures on the disc of the elytron and punctures on the striae of the elytron, which are located close together and having the same appearance and diameter. Measurements were taken with an ocular micrometer calibrated with an calibrated objective slide. Body length was measured from the apex of the longer mandible in closed position to the apex of the longer elytron. The length of the pronotum was measured along the median line including the flange-like base, and the width was determined at the widest part. The length of the elytra was measured from the tip of the basal reflexed lateral margin to the tip of the apex of the longer elytron. The width of the elytron was measured at maximum width of both elytra and represents the general width of the specimen.

Arithmetic means $(\overline{\mathrm{x}})$ are provided for the values measured.

The dissected genitalia were mounted on transparent cards and embedded in polyvinylpyrrolidon, a water soluble medium. These cards are fixed on an object slide and investigated and photographed under a Reichert-Jung Polyvar microscope with magnification up to 400 times. Very helpful is interference contrast 40 , and fluorescence blue stimulation at $450-495 \mathrm{~nm}$, e.g. for the inner structure of the male genitalia.

Habitus photographs were taken with a stereomicroscope Leica M205-C and a Jenoptic ProgRes 5 digital camera using motorised stacking function, subsequently processed with Leica LAS application software, and enhanced with CorelDRAW Graphics Suite X5.

All information given on the labels are displayed in the description chapter verbatim as they appear on the labels.

\section{Taxonomy}

\section{Trilophidius gemmatus sp. $\mathbf{n}$.}

http://zoobank.org/A2138996-D48F-429B-86EF-F626578E9472 Figs 1-5

Types. Holotype: male, dry glued on a paper card pinned, with embedded genitalia on a separate card on the same pin, with printed white label "BHUTAN Thrumshingla NP - Mongar City 20.6.2010 coll. W. MARGGI, THUN" (NMBE).

Paratypes: 7 females, "Bhutan, 20.-27.6.2010 Thrumshingla Mongar city leg. Li Jingke / coll. H.Hebauer (CHR, CBB).

Remarks. In the holotype, the apical spine of the left protibia is missing. In four of the seven paratypes the following joints are missing: one with no left protibia, one with no right middle leg, antennae in one specimen on the right side without joint three and onwards, and in one all tarsus joints are missing at the left middle leg.

Differential diagnosis. A brown Trilophidius species with subelongate elytra having the maximum width behind middle, six setigerous punctures on the third elytral interval, and an incomplete fold-like carina in the channel at the apex of the elytra.

Distinguished from the related species T. impunctatus Putzeys, 1868, by the darker colour, the more robust appearance, the more convex habitus (pronotum and elytron), the internal structure of the male genitalia, and the pattern and shape of setae on the female coxostyli. From the second similar species, T. endroedii Balkenohl, 2001, it differs by the straight labrum, the minute humeral tooth and the male genitalia (all figures of the species mentioned are in Balkenohl 2001).

Description. Measurements: Length $2.30-2.55 \mathrm{~mm}(\overline{\mathrm{x}}=$ $2.42 \mathrm{~mm} *)$, width $0.71-0.81 \mathrm{~mm}(\overline{\mathrm{x}}=0.76 \mathrm{~mm} *)$, ratio length/width of pronotum $0.96-1.06\left(\overline{\mathrm{x}}=1.01^{*}\right)$, ratio length/width of elytra 1.66-1.82 $(\overline{\mathrm{x}}=1.73 *) ;\left({ }^{*} \mathrm{n}=8\right)$.

Colour: Yellowish-brown. Front legs, margins of mandibles, reflexed margin of elytron, pronotum darker. Wings of clypeus yellowish transparent.

Head (Fig. 2): A third smaller than pronotum. Clypeus and wings finely reflexed margined; clypeus straight anteriorly, finely meshed and with minute punctures; wings projecting, rounded off, with fine transverse rugae, fused with clypeus, divided from supraantennal plates by distinct obtuse-angled notches; supraantennal plates not margined, convex, prolonged posteriorly as blunt supraorbital carina, interrupted at mid-eye level; triangular-like tubercle on vertex elongated posteriorly into a short sharp keel. Clypeus and frons divided from supraantennal plates by deep and broad longitudinal furrows. Furrows diverging posteriorly. Frons slightly convex, smooth and with few punctures. Neck constriction distinct at posterior-eye level, composed of small to medium sized irregu- 

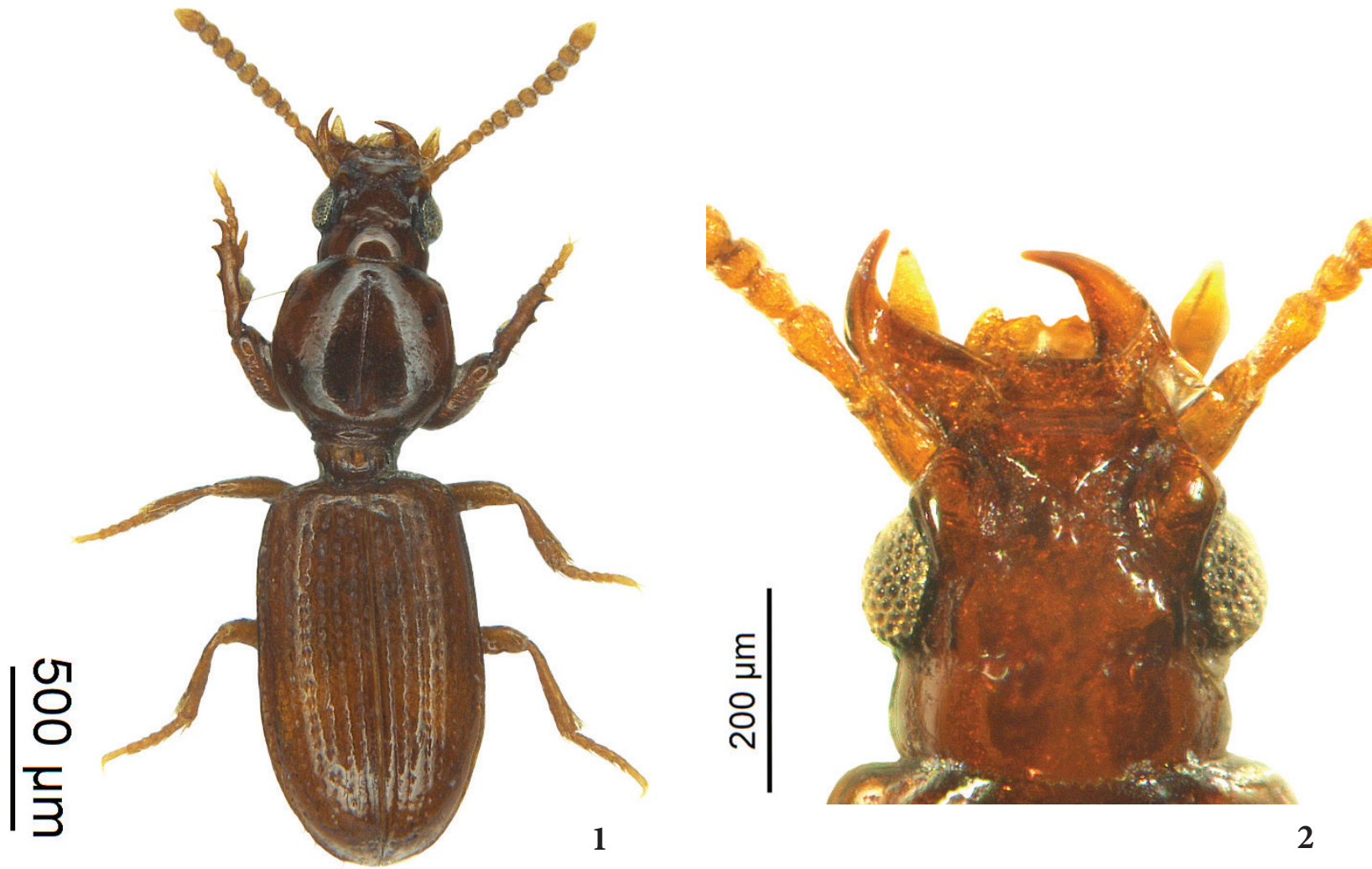

Figures 1-2. Trilophidius gemmatus sp. n., holotype, male, dorsal view. 1 Habitus. 2 Head.

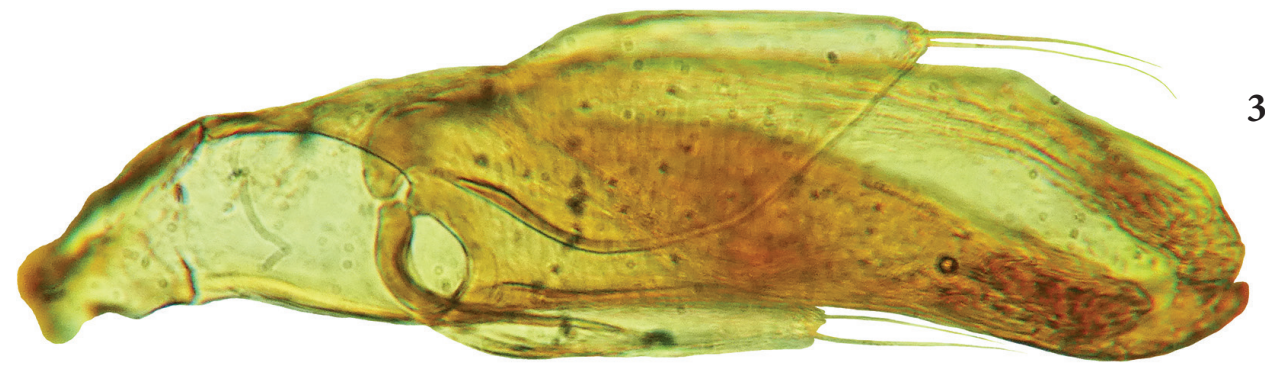

\section{$200 \mu \mathrm{m}$}

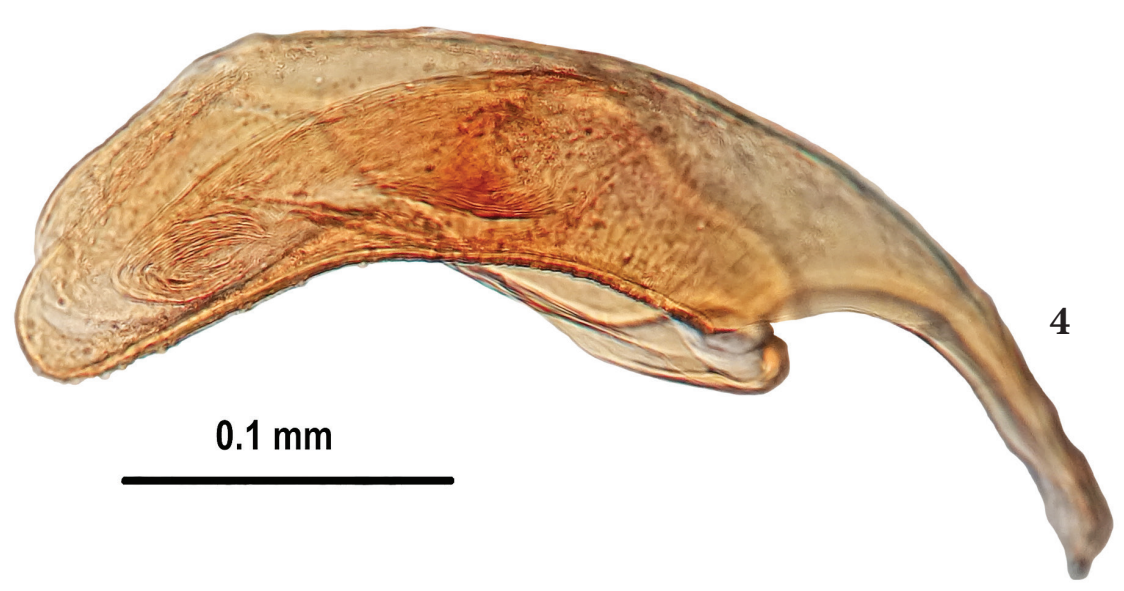

Figures 3-4. Trilophidius gemmatus sp. n., holotype, male genitalia. 3 Overview of the aedeagus with median lobe and parameres, dorsolateral view. 4 Median lobe showing the internal structures of the aedeagus, ventral view. 


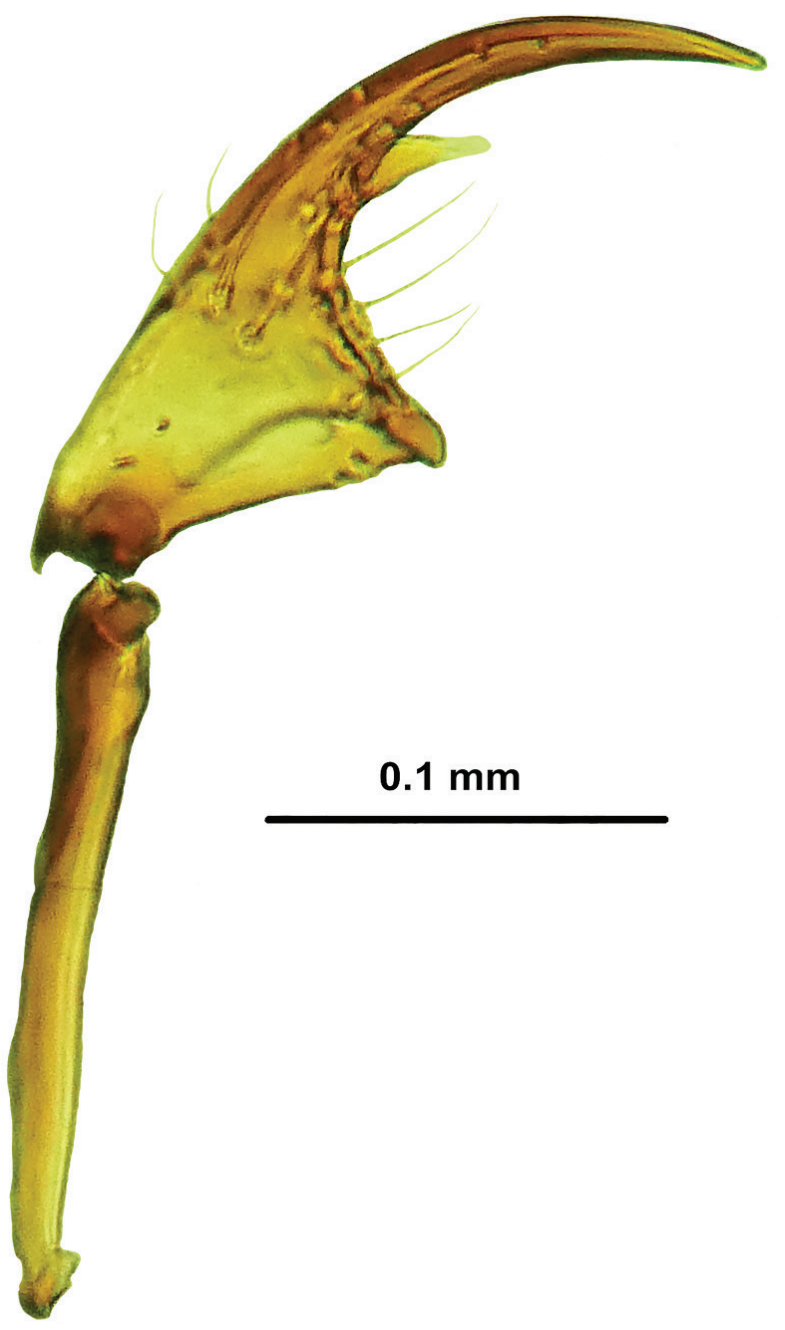

Figure 5. Trilophidius gemmatus sp. n., female coxostyli, paratype, dorsolateral view.

larly arranged band of punctures, interrupted at middle. Eyes large, convex; ommatidia distinct, convex; genae and tempora small. Labrum slightly excised, with indistinct reticulation, five-setose. Mandibles distinctly acute at apex, each with three molares basally.

Apical segment of maxillary palpomere conspicuously securiform, with four setae ventrally; terminal segment of labial palpomere bottle-like, with eight setae, penultimate segment bisetose, ligula with two long apical setae separated, paraglossae slightly broadened at apex. Mentum and submentum divided by deep furrow, with two pairs of setae each, median tooth triangular, small, moderately acute at apex, lobes moderately elongate, much longer than tooth, rounded anteriorly, with longitudinal reticulation. Gula with isodiametric reticulation. Antennae short, just reaching posterior setigerous puncture of pronotum, segment five to ten moniliform.

Pronotum: Outline subglobose, as long as wide, maximum width at middle. Disc convex. Anterior margin nearly straight. Reflexed lateral border distinct from anterior angles to posterior setigerous puncture. Proepisternum distinctly tumid laterally and well visible in dorsal view, most distinct in posterior third. Anterior angles distinct, obtuse-angular, bent downwards. Anterior transverse line visible at anterior angles. Median line distinct, sharp, deeper and broader towards base, not reaching anterior margin, not reaching channel of basal constriction. Surface with some fine irregular transverse wrinkles at median line towards base, with indistinct flat basal impression at each side. Basal ring-like flange, convex, three times as broad as channel of deep basal constriction.

Elytra: Convex in lateral and apical view. Anterior half flattened for a short distance (lateral view). Subelongate, sides slightly rounded anterior middle and diverging, evenly rounded apically. Maximum width slightly behind middle. Base slightly convex truncated. Marginal channel narrowed at middle of elytron, series of umbilical setigerous tubercles interrupted at middle for a short distance often 1-2 tubercles are missing, fold-like carina at apex incomplete; reflexed margin slightly undulate. Humeral tooth indistinct, situated in extended projection of seventh interval.

With two basal tubercles with setigerous punctures adjoining lateral margin at humerus, a distinct tubercle in the extended projection of the second stria. Scutellar stria visible as fine line. First stria deep up to tip of apex, stria two and three fairly deep, punctate-striate, other striae developed as rows of punctures, becoming fine apically; stria five broadly impressed at base, striae two to four shortened at base. Intervals slightly convex, eighths forming obtuse overhanging carina in apical two- fifths, third with series of six setigerous punctures situated at third stria in anterior half and towards the middle of the interval posteriorly.

Hind wings: Fully developed.

Ventral surface: Proepisternum with few transverse wrinkles, fine submarginal furrow visible at anterior angle up to anterior setigerous puncture, furrow between prosternum and proepisternum invisible in anterior third. First and second abdominal sternites with isodiametric meshes; terminal abdominal sternite with irregular reticulation, completely meshed in the male and in apical half in the female (160 times).

Legs: Protibia: Surface smooth; lateral upper spine curved ventrally. Movable spur smaller than spine, nearly straight, apically curved. Preapical lateral denticle robust, sharp, second one smaller. Profemur dorsolaterally with distinct coriaceous notches. Hind legs: Tarsomere one nearly as long as two and three combined.

Male genitalia (Figs 3, 4): Median lobe moderately arcuate, slightly convex in lateral view, with wrinkles and minute pili basally. Spatula at apex spoon like, with nodules. Endophallus without spines. Parameres somewhat distorted, both of them bisetose, petioles of moderate length.

Female genitalia (Fig. 5): Coxostylus one and two fused. Distinctly broadened basally, conspicuously curved and sharp at apex, with 4 dorsal and 5 ventral nematiform setae in the basal half and one big bottle like ensiform seta. The ensiform seta is hyaline apically.

Sexual dimorphism: Terminal abdominal sternites completely meshed with irregular reticulation in the male, and in apical half in the female (160 times). 
Variation: In the eight specimens investigated the number and the arrangement of punctures of the neck constriction varies. In addition, the basal impression on the disc of the pronotum is more or less well developed. It is nearly invisible in two specimens to slightly but well visible in others. The reticulation on the clypeus is more or less distinctly developed (160 times).

Etymology. The name refers to the nodules on the apical part of the aedeagus, which are looking like buds of a flower (in latin gemma; gemmatus = adjective in nominative singular).

Distribution. The species was found in the Thrumshingla National Park, Bhutan. This National Park has an altitude of around $2500 \mathrm{~m}$.

Ecology. Unkown.

\section{Discussion}

In 2001, Asian members of the genus Trilophidius have been revised including descriptions of five new species
(Balkenohl 2001). Although revised, it was emphasized the genus might be much more widely distributed over the Oriental region including mountainous habitats. This assumption was based on the following knowledge: 1 . the genus evolved over tropical Africa with much more species (15), 2. especially the terrestrial fauna of the Oriental Region is still relatively unexplored, and 3. the sister-group of Trilophidius, Trilophus Andrewes, 1927 is known to be distributed over Asia with twenty-eight species (Balkenohl 1999). The present contribution reports firstly evidence for the distinctly wider distribution. It also demonstrates the genus has the dispersal power not only to populate lowland habitats as known before but also alpine regions close to the Palaearctic Region. Interestingly, all Asian species are fully winged and for some formerly described species the ability to flight is documented on labels (e.g. "Lichtfang" or "à la lumiere", respectively "at light") (Balkenohl 2001). Many but not all African species have reduced alae. They are usually collected by shifting litter in forests (Jeannel 1957, Basilewsky 1962, Grebennikov et al. 2017). However, the hypothesis African species developed a higher degree of endemism than Asian species cannot be inferred because sampling on both of the continents is too fragmentary jet.

\section{Updated identification key to the Oriental species of the genus Trilophidius (impunctatus species group)}

1 Sides of elytra with long oval outline, regularly rounded, maximum width at middle. Wings of clypeus distinctly margined. One or both of the parameres with more than 2 more or less long setae ............................................ 2

- Sides of elytra slightly rounded or with straight parts, in any case diverging posteriorly, maximum width behind middle or in $2^{\text {nd }}$ third. Wings of clypeus finely margined or not margined. Parameres with 2 long setae each .................... 4

2 Brown. Supraantennal plates with short sharp vault on top of convexity. Eyes big, regularly subhemispherical. Subapical carina crossing lateral channel of elytron completely. Pronotum without bilateral impression basally. Median lobe of aedeagus two times slightly angled in dorsal view. Length $2.20 \mathrm{~mm}$...... carinatus Balkenohl, 2001

- Yellow to light-brown. Supraantennal plates without short sharp vault on the surface of the convexity. Eyes medium sized, somewhat flattened. Subapical carina incomplete, not crossing lateral channel of elytron. Pronotum with bilateral flat impression at base. Median lobe of aedeagus regularly rounded in dorsal view......

3 Femur of front leg with row of 3 big punctures dorsolaterally. Third interval of elytron with 9 setae. Clypeus straight in middle part, hollowed out transversally in front of tubercle. Surface of pronotum smooth, anterior margin slightly convex. Humerus with small but distinct sharp tooth and $2^{\text {nd }}$ indistinct obtuse tooth. Length $2.33 \mathrm{~mm}$................... fastigatus Balkenohl, 2001

- $\quad$ Femur of front leg with fine transverse rugae dorsolaterally. Third interval of elytron with 8 setae. Clypeus excised, de. clining regularly in front of tubercle. Surface of pronotum with scattered pinprick punctures, anterior margin bisinuate. Humerus with 1 fine tooth. Length $2.10 \mathrm{~mm}$...... minutulus Balkenohl, 2001

4 Medium-brown. Petioles of parameres elongated. Anterior transverse line of pronotum visible. Punctures of striae on elytron bigger, striae deep. Subapical carina incomplete, not crossing lateral channel of elytron. Aedeagus short or nar. rowed in apical half

- Yellow to pale brown. Petioles of parameres short. Anterior transverse line of pronotum absent. Punctures of striae on elytron fairly deep. Subapical carina crossing lateral channel of elytron completely. Aedeagus long, voluminous, with spines and bristles on endophallus. Species of more frail appearance. Length $2.38 \mathrm{~mm}$......impunctatus Putzeys, 1868

5 Neck constriction complete. Labrum slightly bisinuate. Tubercle on clypeus elongated on frons as sharp keel. Anterior margin of pronotum nearly straight, lateral channel of normal size. Length $2.38 \mathrm{~mm}$...... cervilineatus Balkenohl, 2001

- $\quad$ Neck constriction interrupted at middle. Interval three with 6 setigerous punctures. Fold-like carina at apex of the elytron incomplete

6 Labrum slightly excised. Tubercle on clypeus short, not elongated on frons as sharp keel. Anterior margin of pronotum slightly convex, lateral channel broadened anteriorly. Humeral tooth of elytron distinct. Length $2.38 \mathrm{~mm}$

endroedii Balkenohl, 2001

- Labrum straight anteriorly. Tubercle on clypeus moderately developed as sharp keel. Anterior margin of pronotum straight. Petioles of parameres of moderate length. Aedeagus with nodules apically, with aspinose on endophallus. Robust species. Length $2.42 \mathrm{~mm}$.....

gemmatus sp. $\mathrm{n}$. 


\section{Acknowledgements}

I would like to thank Dr Werner Marggi (Thun, Switzerland) and Hans Hebauer (Rain, Bavaria, Germany) for giving me the possibility to study the interesting specimens.

The holotype has been donated to and is deposited in the NMBE.

\section{References}

Balkenohl M (1999) Revision of the genus Trilophus Andrewes from the Oriental region (Coleoptera, Carabidae). Revue Suisse de Zoologie 106: 429-537. https://doi.org/10.5962/bhl.part.80090

Balkenohl M (2001) Key and Catalogue of the Tribe Clivinini from the Oriental Realm, with Revisions of the Genera Thliboclivina Kult, and Trilophidius Jeannel (Insecta, Coleoptera, Carabidae, Scarititae, Clivinini). Pensoft Publishers, Sofia-Moscow, 86 pp.

Balkenohl M (in press) Scaritinae. In: Löbl I, Löbl D (Eds) Catalogue of Palaearctic Coleoptera. Volume 1. Revised and Updated Edition. Archostemata, Myxophaga, Adephaga. Brill, Leiden, Boston, 254-279.

Basilewsky P (1962) Mission zoologique de 1'I.R.S.A.C. en Afrique orientale LX. Coleoptera Carabidae. Annales du Musee Royal de 1'Afrique Centrale 107: 47-337.

Grebennikov VV, Bulirsch P, Magrini P (2017) Four new species, DNA barcode library and pre-Pliocene speciation of the euedaphic Afromontane Clivinini genera Trilophidius and Antireicheia (Coleoptera: Carabidae, Scaritinae). Fragmenta entomologica 49: 1-11. https://doi.org/10.4081/fe.2017.225

Jeannel R (1957) Révision des petits Scaritides endogés voisins de Reicheia Saulcy. Revue Française d'Entomologie, Paris, 24: 129-212. 